\title{
SPECIES-SPECIFICITY OF HUMAN ANTI-BEEF, PORK INSULIN SERUM
}

\author{
By SOLOMON A. BERSON AND ROSALYN S. YALOW \\ (From the Radioisotope Service, Veterans Administration Hospital, Bronx, N. Y.)
}

(Submitted for publication May 18, 1959; accepted July 16, 1959)

Previous studies have revealed the presence of insulin-binding antibodies in the serums of insulin-treated human subjects. Antigen-antibody complexes in this system do not precipitate out of solution but are readily identified by paper chromato-electrophoresis employing insulin- $\mathrm{I}^{\mathbf{1 3 1}}$ (1). Kinetic studies of the reaction between crystalline beef insulin and antiserum have indicated that insulin is probably univalent and that there are at least two distinct orders of antibody-combining sites $(2-4)$. Since insulins from five different mammalian species have been found to differ in amino acid sequence only in positions 8 to 10 of the A (glycyl) chain (5), it appeared of interest to study the reactivity and cross reactivity of these various insulins in the same antiserum. Studies with human insulin, several different preparations of beef insulin, including beef desamido insulin, and the $\mathrm{A}$ and $\mathrm{B}$ chains of insulin are also reported.

\section{MATERIALS AND METHODS}

The following species-specific insulins and insulin fractions ${ }^{1}$ were labeled with $\mathrm{I}^{131}$ : beef insulin (Lilly, Lot No. 535664), pork insulin (Lilly, Lot No. 499667), horse insulin, sheep insulin, beef insulin (Boots ${ }^{2}$ ), desamido insulin derived from the Boots beef insulin by countercurrent fractionation by Dr. Lyman Craig, A chain and $B$ chain of beef insulin. All the aforementioned insulins were crystalline preparations. A crude prepara-

1 We are greatly indebted to Doctors O. H. Behrens and C. W. Pettinga for supplies of the Lilly beef and pork insulins, to Dr. Hans Neurath for the horse insulin, to Dr. L. Craig for Boots beef insulin, desamido insulin, sheep insulin, and $A$ and $B$ chains, and to Doctors $F$. Tietze and J. Field for human insulin. The Lilly beef and pork insulins assayed at 27 to 29 units per mg. and the horse insulin at 25 units per $\mathrm{mg}$. in the Lilly laboratories. The Boots beef insulin assayed at 21 to 23 units per mg. in the Boots laboratories but this insulin is said to be comparable in purity to that of the Lilly preparations (6). The desamido insulin showed the same hormonal potency as the parent preparation (6).

2 Standardized sample of insulin from the Commission on Proteins, IUPAC. tion of human insulin (1.8 units per $\mathrm{mg}$. $)^{3}$ was used in competitive cross reaction experiments but was not labeled. The insulins were labeled with an average of less than 0.6 iodine atom per molecule 6,000 molecular weight insulin and at specific activities of 10 to $40 \mathrm{mc}$. $\mathrm{I}^{131}$ per mg. insulin. The methods employed in preparation and in protection against severe radiation damage have been described previously $(1,7)$.

Mixtures containing trace amounts of $\mathrm{I}^{\mathbf{1 3 1}}$-labeled insulin and various concentrations of unlabeled insulin from the same or different animal species were incubated together with antiserums at $37^{\circ} \mathrm{C}$. for four hours. Aliquots were then applied to paper strips for hydrodynamic flow chromatography and electrophoresis at $4^{\circ} \mathrm{C}$. The conditions employed for these runs as well as the assay of radioactivity on the strips by means of an automatic strip counter have been described in detail previously (1). Chromatographic or electrophoretic separation of free insulin and insulin bound to antibody depends on the adsorption of free insulin to the paper at the site of application $(1,8)$ while antibody-bound insulin migrates with the inter- $\gamma$ - $\beta$-globulins (9). The amounts of free insulin and bound insulin in each mixture were determined from the areas under the respective peaks of radioactivity in the two positions.

No differences in the binding of $\mathrm{I}^{131}$-labeled insulin and unlabeled insulin from the same species could be detected, i.e., at any particular insulin concentration, the same degree of binding of insulin- $\mathrm{I}^{\mathbf{1 3 1}}$ was observed whether the insulin present was derived entirely from the preparation of $\mathrm{I}^{131}$-labeled insulin or was primarily uniodinated insulin with only a tracer amount of iodoinsulin. It is assumed, therefore, that immunologic reactivity of insulin is not altered by the labeling procedure employed here. Analytic methods for determination of equilibrium constants and standard free energy changes have been described (4).

\section{RESULTS}

Data are presented in plots of the ratio of bound insulin- $\mathrm{I}^{131}$ to free insulin- $\mathrm{I}^{131}(\mathrm{~B} / \mathrm{F})$ as a function of the total insulin concentration present. It has been shown elsewhere (4) that, at concentrations of insulin negligible compared to the concen-

${ }^{3}$ The concentration of human insulin in this preparation was based on the assumption that pure human insulin would contain 28 units per $\mathrm{mg}$. Accordingly, $1 \mathrm{mg}$. of crude preparation was taken to represent $64.5 \mu \mathrm{g}$. human insulin. 
tration of antibody ("trace insulin concentrations"), the ratio $\mathrm{B} / \mathrm{F}$ is the sum of the products of antibody concentration and equilibrium constant for each reaction between insulin and the different antibodies which may be present. Thus, for the same antibody concentration a higher $B / F$ value is indicative of a higher equilibrium constant $(K)^{4}$

${ }^{4} \mathrm{~K}=\frac{[\text { Ins- } \mathrm{Ab} \text { complex] }}{[\text { Ins }][\mathrm{Ab}]}$, where $\mathrm{Ab}$ denotes antibody and the square brackets denote molar concentrations.
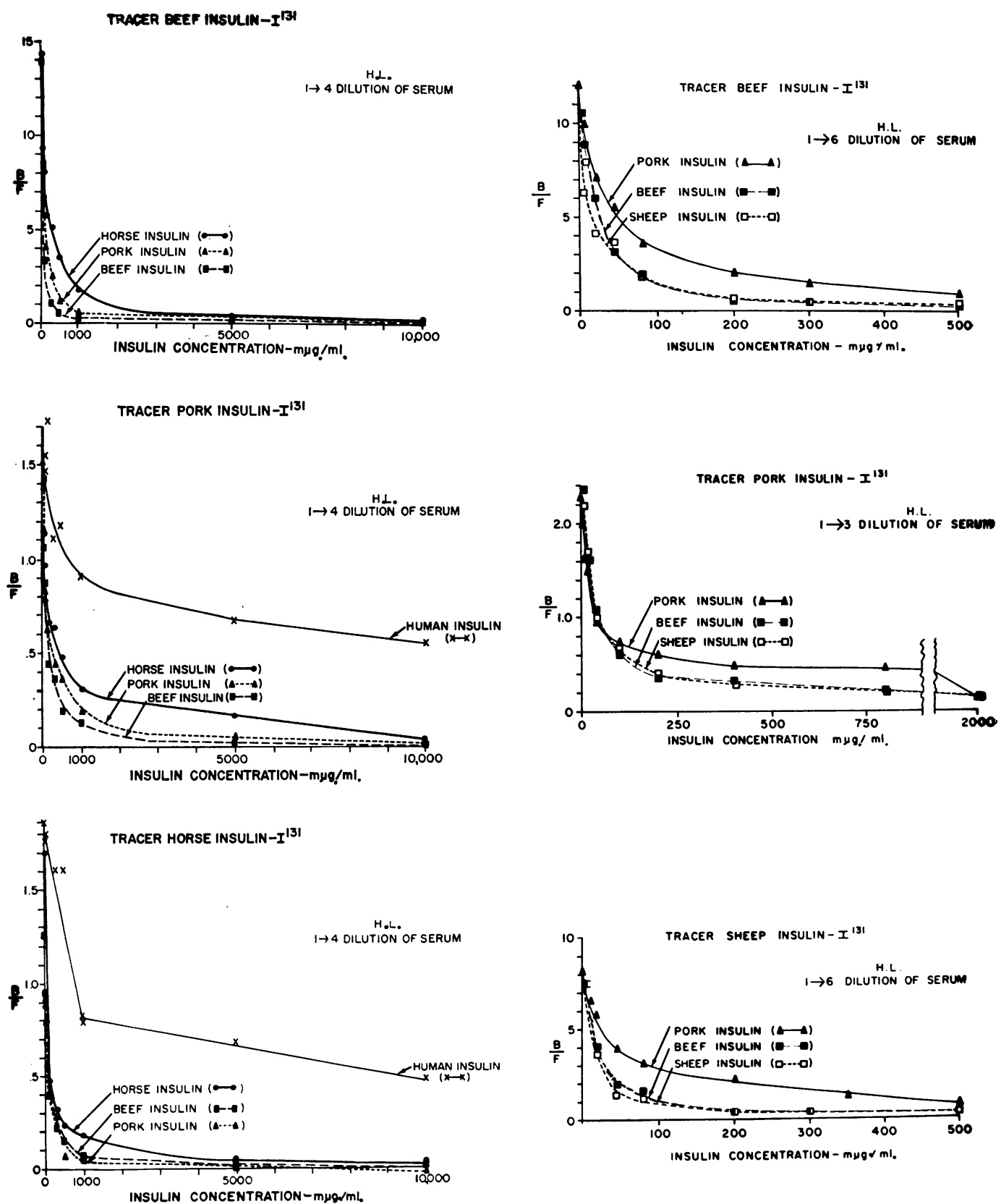

Fig. 1. Subject H. L. Ratio of Bound Insulin-I ${ }^{131}$ to Free Insulin-I ${ }^{181}(B / F)$ as a Function of Concentration of Various Unlabeled Insulins

Human insulin in the concentrations employed failed to lower the ratio for beef insulin- ${ }^{181}$ significantly at $1: 4$ dilution of serum but did do so at higher serum dilutions. Except where otherwise indicated, beef insulin is Lilly beef insulin. 

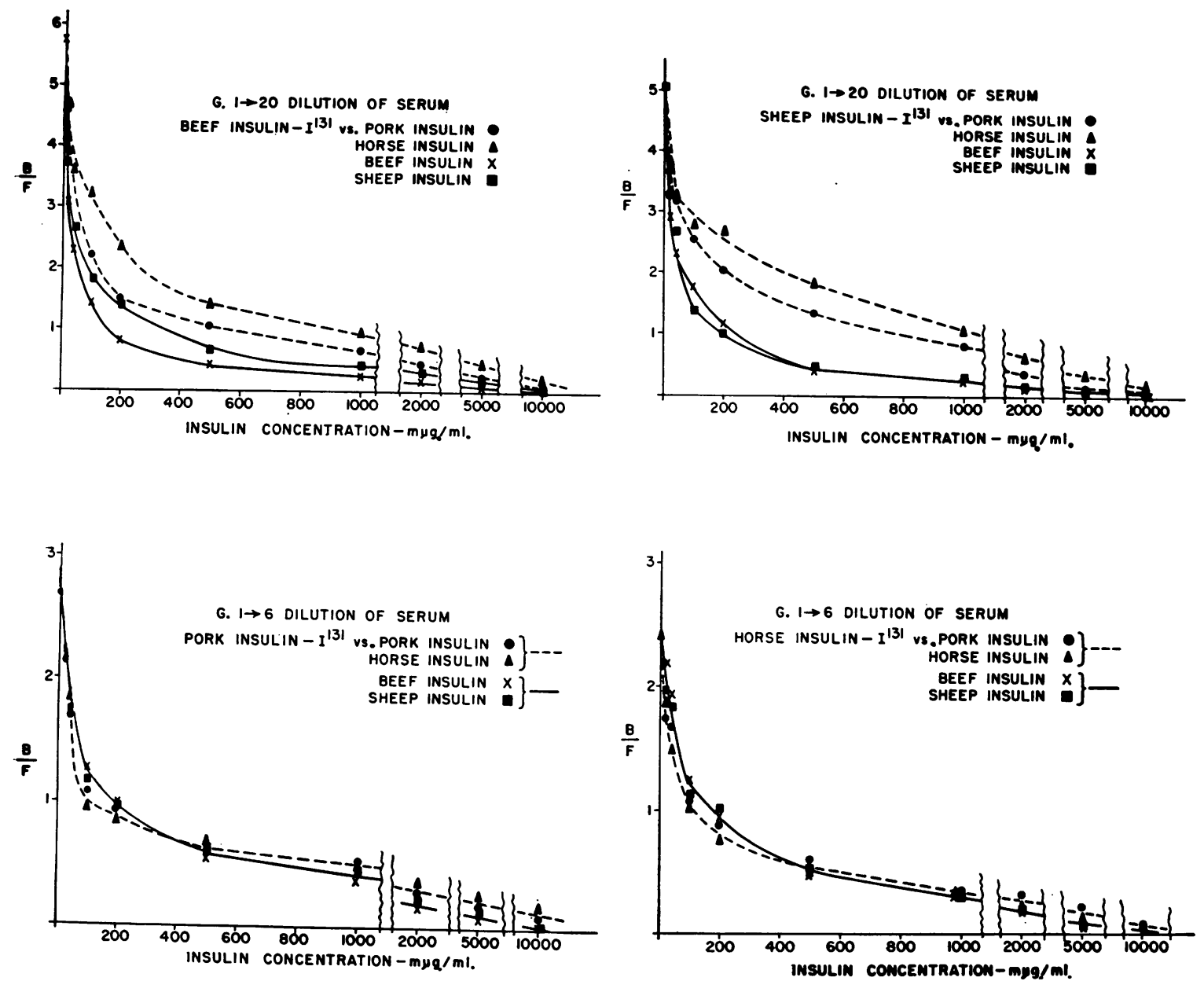

Fig. 2. Subject G. Ratio of Bound Insulin-I ${ }^{19}$ to Free Insulin-I ${ }^{19}$ (B/F) as a Function of Concentration of VARIOUS UNLABELED Insulins

for the reaction between insulin and that antibody. It has also been shown that the $B / F$ ratio at trace insulin concentrations falls proportionately with dilution of the serum.

In most antiserums the $B / F$ ratio at trace concentrations of beef insulin- $\mathrm{I}^{131}$ is significantly greater than the $\mathrm{B} / \mathrm{F}$ ratio for pork insulin- $\mathrm{I}^{131}$ or horse insulin- $\mathrm{I}^{\mathbf{1 3 1}}$ under the same conditions. In the present series of three antiserums, which have been studied in some detail, a similar pattern was observed in two cases (H. L. and G., Figures 1 and 2 ) but in the third case (L. J., Figure 3 ) the differences among the different species-specific insulins, although definite, were small. Since the experiments in L. J. and G. were done with the same preparation of $\mathrm{I}^{131}$-labeled insulin, it is clear that differences in reaction among the different species' insulins are not attributable to alterations of insulin during the labeling procedures. It should also be emphasized that experiments with the same antiserum and different preparations of the same species' insulin yield reproducible results. In $\mathrm{H}$. L. and G. the binding of beef insulin- $\mathrm{I}^{131}$ and sheep insulin- $\mathrm{I}^{131}$ was much greater than the binding of horse insulin- $\mathrm{I}^{131}$ and pork insulin- $\mathrm{I}^{181}$ at trace insulin concentrations and at the same dilution of antiserum. In order to obtain convenient $B / F$ ratios over a wide range of insulin concentrations it was therefore necessary to employ different dilutions of antiserum in the different experiments. When account is taken of the serum dilution factors it is seen that the $B / F$ ratios at trace insulin concentrations in the absence of added unlabeled insulins were about 7 to 10 times as great for beef insulin- $\mathrm{I}^{131}$ and sheep insulin- $\mathrm{I}^{131}$ as for pork insulin- $\mathrm{I}^{131}$ and horse in- 

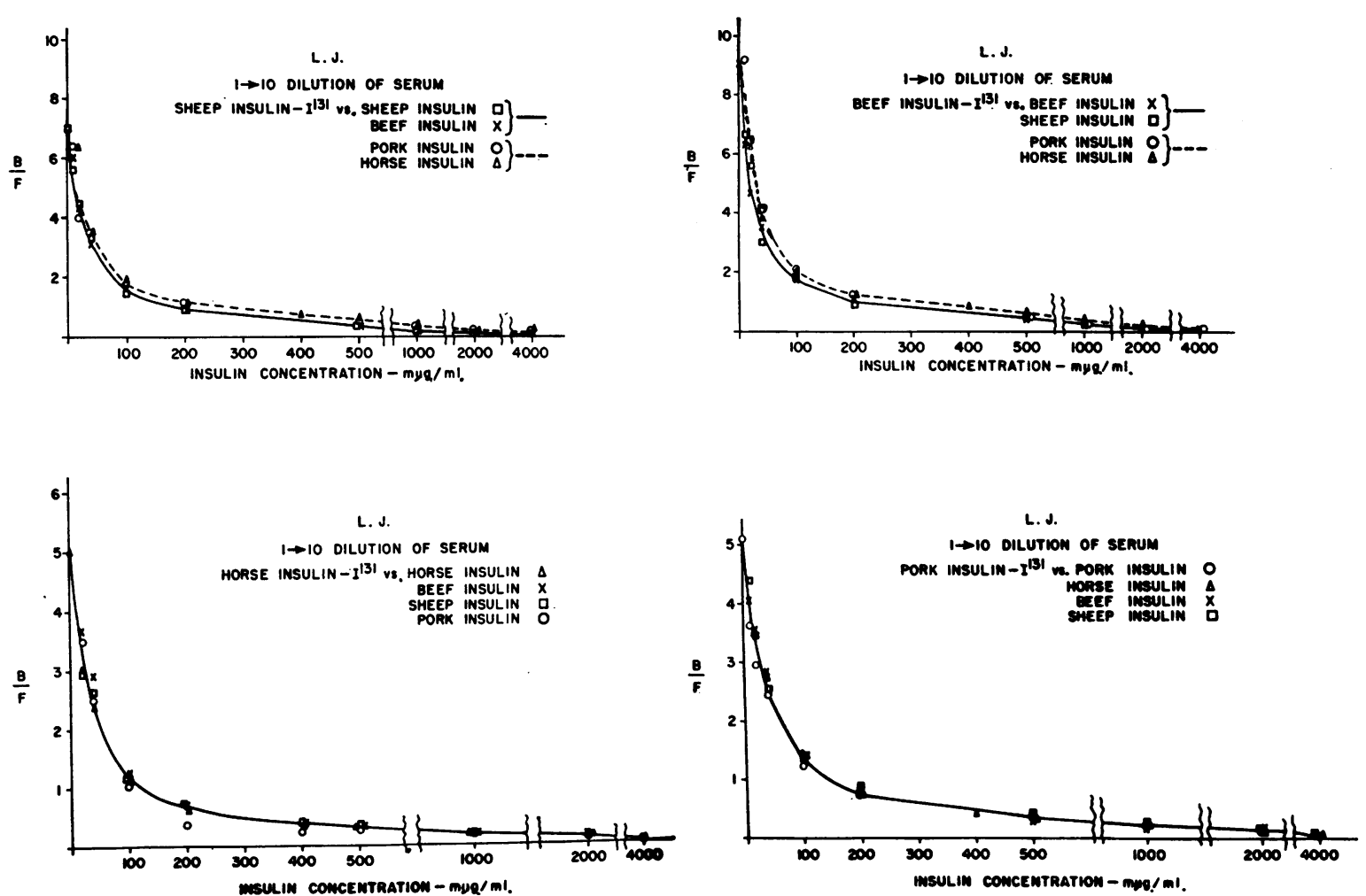

Fig. 3. Subject L. J. Ratio of Bound Insulin-I ${ }^{181}$ to Free Insulin-I ${ }^{181}$ (B/F) as a Function of ConcentraTION OF VARIOUS UNLABELEd INSULINS

sulin- $\mathrm{I}^{131}$ in both H. L. and G. (compare ordinate intercepts of the separate frames in Figures 1 and 2 with attention to the dilution factors). However, the total binding capacities for the different insulins at high insulin concentrations did not differ significantly in the same antiserum (Table I).

In experiments in which the labeled insulin was derived from the same species as the unlabeled insulin it is possible to determine the actual amount

TABLE I

Binding characteristics of various insertions in the serum of Subject $G$

\begin{tabular}{|c|c|c|c|c|}
\hline $\begin{array}{l}\text { Insulin } \\
\text { species }\end{array}$ & Site & Binding capacity & $\mathrm{K}$ & $\Delta \mathrm{F}^{\circ}$ \\
\hline \multirow{2}{*}{ Beef } & “a” & $66 \times 10^{-9}$ Moles $/ L$ & $1.4 \times 10^{9} \mathrm{~L} . /$ Mole & -12.8 Kcal./Mole \\
\hline & "b" & $\frac{682}{748^{*}}$ & 0.032 & -10.5 \\
\hline \multirow{2}{*}{ Sheep } & “a” & 100 & 0.8 & -12.5 \\
\hline & "b" & $\frac{734}{834^{*}}$ & 0.027 & -10.4 \\
\hline \multirow{2}{*}{ Pork } & “a” & 30 & 0.38 & -12.0 \\
\hline & "b" & $\frac{720}{750^{*}}$ & 0.0066 & -9.6 \\
\hline \multirow{2}{*}{ Horse } & “a”, & 40 & 0.31 & -11.9 \\
\hline & "b" & $\frac{708}{748^{*}}$ & 0.0034 & -9.2 \\
\hline
\end{tabular}

* Total binding capacity. 
of bound insulin (B) from the insulin concentration and the percentage of insulin- $\mathrm{I}^{131}$ which was observed to be bound. In L. J. and G., B/F has been plotted as a function of $B$ for the individual species-specific insulins (Figures 4 and 5). A great similarity is observed between beef and sheep insulin on the one hand and pork and horse insulin on the other. Experimental data for beef insulin reacting with human anti-beef, pork insulin serum have been shown to be compatible with a theoretical model of a univalent insulin reacting with two orders of antibody combiningsites (4). The curves in Figure 5 are theoretical curves fitted (4) for the equilibrium constants and antibody concentrations for each of these two sites as given in Table I. The "a" sites contribute primarily to the sharp upsweep of the curves in the region of low $B$, whereas binding of insulin to the " $\mathrm{b}$ " sites is reflected in the terminal shallow slopes of the $B / F$ vs. B curves.

On competitive cross reaction, unlabeled insulins of all animal species are capable of blocking completely the binding of any of the labeled insulins (Figures 1 through 3 ), indicating that all sites available to any single species' insulin are likewise available to all the other insulins. However, in G. and H. L. (Figures 1 and 2) the concentration of unlabeled insulin required to reduce the binding of an $\mathrm{I}^{131}$-labeled insulin to any arbitrary level depended on the species-specific insulin employed. In general, beef and sheep insulins were the strongest competitors against any of the labeled insulins, except that at low insulin concentrations pork and

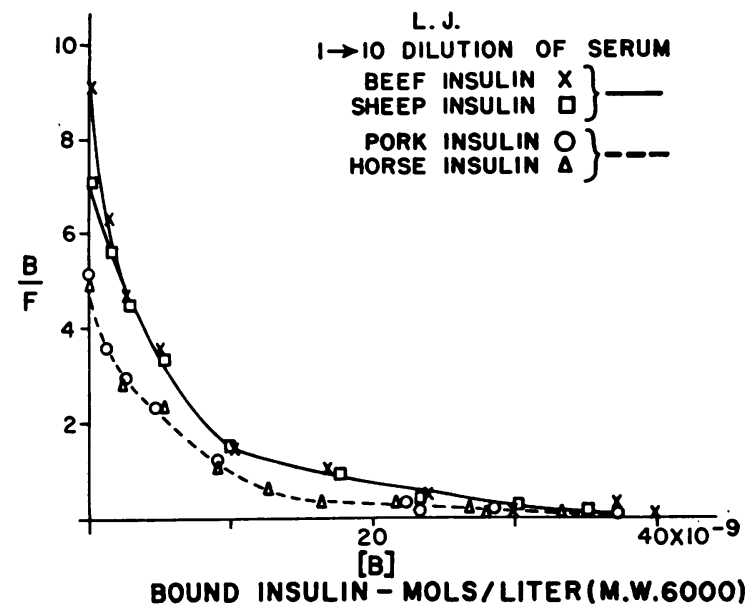

Fig. 4. Subject L. J. Ratio of Bound to Free Insulin (B/F) as a Function of the Concentration of Bound Insulin (B) For Various Animal Insulins

horse insulins competed as well or better against their homologous labeled insulin. Human insulin competed weakly (Figure 1) and was not employed in high enough concentrations in these cases to demonstrate that it can block all sites available to the animal insulins. However, with antiserums of binding capacities of 10 to $20 \mathrm{~m} \mu \mathrm{g}$. per $\mathrm{ml}$. for beef insulin, human insulin at $10 \mu \mathrm{g}$. per $\mathrm{ml}$. does inhibit completely the binding of beef insulin- $\mathrm{I}^{131}$.

Lilly beef insulin, Boots beef insulin and desamido insulin derived from the latter all competed identically against Lilly beef insulin- $\mathrm{I}^{131}$ in $\mathrm{G}$. (Figure 6). Furthermore, binding of all three labeled insulins was inhibited identically by un-
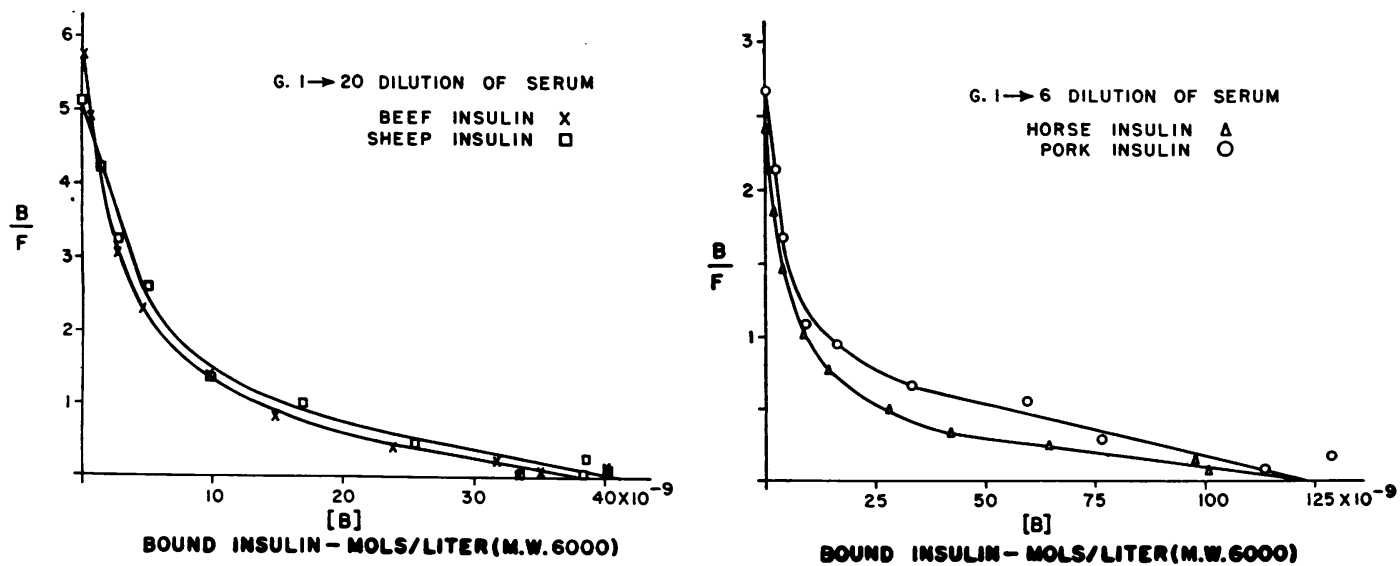

Fig. 5. Subject G. Ratio of Bound to Free Insulin (B/F) as a Function of the ConcentraTION OF Bound Insulin (B) For Various ANimal Insulins 

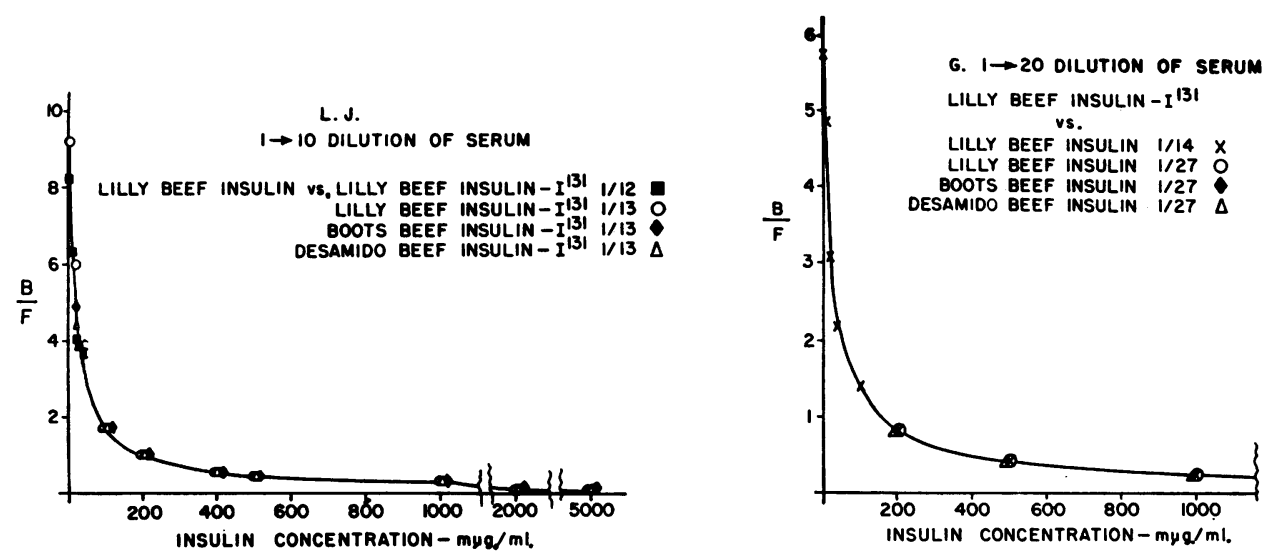

Fig. 6. B/F Ratios for Various I Isi-Labeled Insulins as a Function of the Concentration of Unlabeled Lilly BeEF Insulin in L. J. (LeFt) and B/F Ratios for Lilly Beef Insulin-I ${ }^{121}$ as a Function of Concentration of Different Preparations of Unlabeled BEEF INSULIN IN G. (RIGHT)

The three concentrations of Lilly (1/27), Boots and desamido (Boots) beef insulins tested in G. were in the range in which the most marked differences among the different animal species' insulins were observed (see Figure 2).

labeled Lilly beef insulin in the serum of L. J. (Figure 6).

Neither labeled A chain nor labeled B chain in trace concentrations was observed to bind to the undiluted serum of G., nor did these chains inhibit binding of beef insulin- $\mathrm{I}^{131}$ when present at concentrations of $250 \mu \mathrm{g}$. per $\mathrm{ml}$. in antiserums with maximum insulin-binding capacities $<50$ $\mathrm{m} \mu \mathrm{g}$. per $\mathrm{ml}$.

Mixtures of the amino acids threonine, glycine and isoleucine ( $1 \mathrm{mg}$. per $\mathrm{ml}$.) and of the dipeptide alanyl-serine ( $5 \mathrm{mg}$. per $\mathrm{ml}$.) did not inhibit binding of beef insulin- $\mathrm{I}^{131}$ or pork insulin- $\mathrm{I}^{\mathbf{1 3 1}}$.

\section{DISCUSSION}

Previous studies of insulin cross reactions by techniques employing sensitized guinea pig uterus and anaphylaxis (10), complement fixation (11), neutralization in the mouse convulsion test (12) and sensitized red cell hemagglutination (13) have suggested immunological identity or similarity of insulins from different species. However, it is questionable whether any of these techniques permits precise quantitative determination of small differences in reaction with antibody although Lewis (10) did observe slight differences between beef and pork insulin in the reaction with sensitized guinea pig uterus. In some instances gross immunological differences among various insulins have been commented upon, e.g., Moloney and Coval (12) found that certain preparations of guinea pig and sheep insulins were neutralized by homologous antiserums whereas the endogenous insulins were not neutralized. Also, Lowell (14) had observed that 30 units of human insulin was capable of inducing a decrease in blood sugar in human subjects resistant to a similar dose of crystalline beef-pork insulin and concluded that human and animal insulins were immunologically different. Lerman (15) correctly pointed out that the reaction of antiserum would be expected to be greater with insulins of other species than with insulin from the antiserum donor and emphasized that "any biological protection test is undoubtedly too crude to detect slight amounts of antibodies to an antigen derived from the same species as the antiserum is derived." The inability of Burrows, Peters and Lowell (16) to demonstrate competitive inhibition of binding of beef insulin- $\mathrm{I}^{\mathbf{1 3 1}}$ by human insulin can be attributed to inadequate concentrations of human insulin used with insulin-resistant serums. The present studies have not only demonstrated the reaction of human insulin with human anti-beef, pork insulin serums but show also that, in concentrations sufficiently high compared to the maximum insulin-binding capacity of the serums, human insulin can occupy all the antibody combining-sites.

The similar total binding capacities for beef, 
sheep, pork and horse insulins in individual serums and the ability of each species' insulin to inhibit completely, by competition, the binding of any other species' insulin indicate that the speciesspecific differences in binding and competitive inhibition are to be explained not on the basis of reactions with different antibody combining-sites but on the basis of energetically different reactions with the same antibody combining-sites. It is important to note here that the similarly reacting insulins show a closer chemical kinship with each other than with the dissimilarly reacting insulins. Thus beef insulin, with the sequence ala., ser., val. in the eighth, ninth and tenth positions, respectively, of the A chain, shares two amino acids in this site with sheep insulin (ala., gly., val.) whereas horse insulin (thr., gly., ileu.) shares two amino acids with pork insulin (thr., ser., ileu.).

The marked differences (in most antiserums) in direct and cross reaction of four different insulins which differ, at least insofar as amino acid sequence is concerned, only in the site comprising the eighth to tenth residues of the glycyl chain, indicate that this region is a site of antigenic determinacy. Since most commercial insulin preparations are approximately equal mixtures of beef and pork insulin it might be supposed that antibody specificity is directed toward the amino acids in the eighth to tenth positions of both proteins (independent of the possibility that other insulin sites may also be antigenic in man). It is not unreasonable to infer further that the degree of spatial complementarity ${ }^{5}$ of the antibodies developed towards the ala., ser., val. sequence of beef insulin is greater than that of the antibodies directed against the thr., ser., ileu. sequence of pork insulin. However, both groups of antibodies are able to react with insulins of other species sharing none of the three particular residues of the original antigen (viz., sheep insulin inhibits binding of pork insulin and horse insulin inhibits binding of beef insulin), although the energies of the reactions of the various insulins differ significantly. The greatest difference is seen between the reactions of horse insulin and of beef (or

\footnotetext{
5 Neither this word nor "complementariness" is given in Webster's unabridged or the Century Dictionaries. The proper word appears to be complementarism. Nevertheless, "complementarity" is sufficiently entrenched in the scientific parlance as to justify its continued usage.
}

sheep) insulin with the "b" antibody sites. Here the equilibrium constants differ by a factor of 8 to 10 which indicates a difference of about $1.3 \mathrm{Kcal}$. in the standard free energy changes of the reactions. In general, the differences in reaction of the various insulins are greater with the " $b$ " sites than with the "a" sites. This conclusion could be deduced also from the cross reaction experiments in which the differences were generally more marked at the higher insulin concentrations. Since the equilibrium constants (see Reference 4 for methods of evaluation) for horse insulin with "a" and "b" antibody sites are $3.1 \times 10^{8} \mathrm{~L}$. per Mole $\left(\Delta \mathrm{F}^{\circ}=-11.9 \mathrm{Kcal}\right.$. $)$ and $3.4 \times 10^{\circ} \mathrm{L}$. per Mole $\left(\Delta \mathrm{F}^{\circ}=-9.2 \mathrm{Kcal}\right.$. $)$, respectively, the difference in $\Delta \mathrm{F}^{\circ}$ between the reactions for horse insulin (the weakest reacting animal insulin) and beef (or sheep) insulin still represents only a relatively small part of the total free energy change. However, a more' extensive study might well reveal much greater differences in some antiserums.

Aside from the relatively high binding energy compared to that of other antigen-antibody reactions which has been commented on elsewhere (2), perhaps the most interesting aspect of the insulin-antibody system is the chemical nature of the reaction site on the antigen. In the case of sheep insulin, none of the amino acid $\mathrm{R}$ groups in the sequence 8 to 10 contains any permanently polarized group, i.e., there are no charged (ionic) or hydrogen binding sites on the $\mathrm{R}$ groups although the N's of the peptide bond backbone undoubtedly have residual positive charges which would not be expected to differ among the various insulins. Furthermore, since sheep insulin reacts almost as well as beef insulin and more strongly than horse and pork insulins, little importance can be attributed to the hydroxyl groups of serine and threonine in the binding energy. It seems reasonable to conclude therefore that at least the maximum differences in energy of binding (and perhaps a significant fraction of the energy of binding) for the various insulins are attributable to van der Waals' forces alone, and that close spatial complementarity between antigen and antibody (rather than the attraction of oppositely charged polar groups) characterizes the site of this antigen-antibody reaction. Yet this conclusion cannot be made without reservation. If complementarity extends over an area consider- 
ably larger than the antigenic site itself, several polar groups of the insulin molecule might be involved in the reaction. The differences in reactivity among the different insulins might then simply be due to steric restrictions (the eighth and tenth residues in the $A$ chains of horse and pork insulins have an extra methyl group over those of beef and sheep insulins) in a relatively small region of a larger reaction site that is bound to the antibody primarily by charged groups. According to this hypothesis, the antigenic determinacy which stimulates antibody formation may reside in a completely non-polar site but the antibody directed toward the antigenic site may be spatially and otherwise complementarily adapted to a larger surface of the antigen than the antigenic site itself through polar as well as non-polar linkages. Even if this were the case, however, the stronger binding of sheep than of horse insulin would have to be interpreted in terms of spatial complementarity. Another reservation would be concerned with the possibility that differences in the amino acid sequence 8 to 10 of the glycyl chain are accompanied by other differences in the helical configurations of the various insulins. However, in the absence of definite information on this point, further speculation is unwarranted.

The greater reaction of sheep insulin (which is not one of the original antigens) than of pork insulin (which is one of the original antigens) could obviously be explained by postulating that most (or all) of the antibody is directed toward beef insulin which bears a closer resemblance to sheep insulin than to pork insulin. However, there is no direct evidence bearing on this point and from preliminary studies in animals, in which single species' insulins are used as antigens, it appears as if this explanation may not be completely satisfactory. It should be emphasized strongly that these studies do not exclude a second antigenic site or a second site of reaction. Since the amino acid sequences are apparently elsewhere identical in all the different species' insulins employed here, their reactions at other sites would probably not be distinguishable in any event.

The absence of detectable reaction with labeled $B$ chain was perhaps not unexpected. The lack of reaction of labeled $A$ chain is to be explained on two bases. Firstly, this peptide is in a very much extended state as compared to its configura- tion within the intact insulin molecule since Craig (6) has found that on differential dialysis "it behaves like a molecule of changing molecular size mostly much larger than would be expected." Secondly, during the splitting of insulin the intraA-chain disulfide bridge between 6 and 11 is broken with the formation of cysteic acid residues which might well provide insuperable obstacles to binding of the site in question. It is also of interest to note that $\mathrm{I}^{131}$-labeled $\mathrm{A}$ chain alone of all insulin preparations ( $B$ chain included) fails to bind to paper strips but migrates faster than albumin on electrophoresis in veronal buffer (consistent with the acidic nature of the A chain).

\section{SUMMARY AND CONCLUSIONS}

1. Crystalline pork, sheep, horse, beef (two preparations) and beef desamido insulins and $A$ and $B$ chains of beef insulin were labeled with $\mathrm{I}^{131}$.

2. The labeled insulin preparations were tested directly in reactions with insulin-binding antibodies in human anti-beef, pork insulin serums and were cross reacted in various combinations with unlabeled insulins of all species as well as with unlabeled human insulin.

3. No differences were observed in the extent to which the two preparations of beef insulin- ${ }^{131}$ and desamido beef insulin- $\mathrm{I}^{\mathbf{1 3 1}}$ reacted with insulin-binding antibodies or in the degree to which each of the unlabeled beef preparations competed against the binding of one of the $\mathrm{I}^{131}$-labeled beef insulins.

4. In general, beef and sheep insulins were bound more strongly than pork or horse insulins in both direct and cross reaction studies. These similarities are paralleled by known chemical similarities among the different animal species' insulins. Human insulin cross reacted less strongly than did any of the animal insulins.

5. The observed differences and similarities in binding of the various animal insulins suggest that the site of differences in amino acid sequence (residues 8 to 10 of the $A$ chain) constitutes at least part of the antigenic site as well as of the site of reaction with the antibody.

\section{ACKNOWLEDGMENTS}

We are indebted to Dr. Elvin A. Kabat for helpful comments and a critical review of the manuscript. We 
also wish to thank Frieda Steiner and Eve Spelke for secretarial assistance and the Department of Medical Illustration for the figures.

\section{REFERENCES}

1. Berson, S. A., Yalow, R. S., Bauman, A., Rothschild, M. A., and Newerly, K. Insulin- $I^{131}$ metabolism in human subjects: Demonstration of insulin binding globulin in the circulation of insulin treated subjects. J. clin. Invest. 1956, 35, 170.

2. Berson, S. A., and Yalow, R. S. Kinetics of reaction between insulin and insulin-binding antibody (abstract). J. clin. Invest. 1957, 36, 873.

3. Berson, S. A., and Yalow, R. S. Isotopic tracers in the study of diabetes. Advanc. biol. med. Phys. 1958, 6, 350.

4. Berson, S. A., and Yalow, R. S. Quantitative aspects of the reaction between insulin and insulin-binding antibody. J. clin. Invest. 1959, 38, 1996.

5. Harris, J. I., Sanger, F., and Naughton, M. A. Species differences in insulin. Arch. Biochem. 1956, 65, 427.

6. Craig, L. C. Personal communication.

7. Berson, S. A., and Yalow, R. S. Radiochemical and radiobiological alterations of $\mathrm{I}^{181}$-labeled proteins in solution. Ann. N. Y. Acad. Sci. 1957, 70, 56.
8. Kallee, E. Über J-signiertes Insulin. I. Mitteilung (Nachweis). Z. Naturforsch. 1952, 76, 661.

9. Berson, S. A., and Yalow, R. S. Ethanol fractionation of plasma and electrophoretic identification of insulin-binding antibody. J. clin. Invest. 1957, 36, 642.

10. Lewis, J. H. The antigenic properties of insulin. J. Amer. med. Ass. 1937, 108, 1336.

11. Wasserman, P., and Mirsky, I. A. Immunological identity of insulin from various species. Endocrinology 1942, 31, 115.

12. Moloney, P. J., and Coval, P. J. Antigenicity of insulin: Diabetes induced by specific antibodies. Biochem. J. 1955, 59, 179.

13. Arquilla, E. R., and Stavitsky, A. B. Evidence for the insulin-directed specificity of rabbit anti-insulin serum. J. clin. Invest. 1956, 35, 467.

14. Lowell, F. C. Evidence for the existence of two antibodies for crystalline insulin. Proc. Soc. exp. Biol. (N. Y.) 1942, 50, 167.

15. Lerman, J. Insulin resistance. The role of immunity in its production. Amer. J. med. Sci. 1944, 207, 354.

16. Burrows, B. A., Peters, T., and Lowell, F. C. Physical binding of insulin by gamma globulins of insulin-resistant subjects. J. clin. Invest. 1957, 36, 393. 